\title{
Enhanced Reduction and Determination of Trace Thyroxine at Carbon Paste Electrode in the Presence of Trace Cetyltrimethylammonium Bromide
}

\author{
Chengguo Hu,* Qiong He,*,** Qing LI,* and Shengshui Hu*广 \\ * Department of Chemistry, Wuhan University, Wuhan 430072, China \\ **Department of Chemistry, Qujing Normal College, Qujing 655000, China
}

\begin{abstract}
The electrochemical response of thyroxine $\left(\mathrm{T}_{4}\right)$ at a carbon paste electrode (CPE) in the presence of cetyltrimethylammonium bromide $(\mathrm{CTAB})$ was investigated. It gave a well-defined oxidation peak at $0.80 \mathrm{~V}$ and a sensitive reduction peak at $0.40 \mathrm{~V}$. Compared with the indiscernible signal in the absence of CTAB, the reduction current of $\mathrm{T}_{4}$ at $\mathrm{CPE}$ was greatly enhanced in the presence of $\mathrm{CTAB}$, due to the interactions between $\mathrm{T}_{4}, \mathrm{CTAB}$ and the hydrophobic electrode surface. The electrode process of $\mathrm{T}_{4}$ was explored by cyclic voltammetry and chronocoulometry. The effect of surfactants on the reduction reaction proved that bromide ions $\left(\mathrm{Br}^{-}\right)$in $\mathrm{CTAB}$ might form special ion complexes with $\mathrm{T}_{4}$ via a special interaction with the iodine atoms on $\mathrm{T}_{4}$, which would activate the reduction of $\mathrm{T}_{4}$. The sensitive and selective reduction of $\mathrm{T}_{4}$ in this system was applied to the determination of $\mathrm{T}_{4}$ in drugs; a detection limit of $6.5 \times 10^{-9} \mathrm{M}$ was obtained $(\sigma=3)$.
\end{abstract}

(Received February 12, 2004; Accepted April 13, 2004)

\section{Introduction}

Thyroxine $\left(\mathrm{T}_{4}\right)$ is an important substance produced in thyroid glands. The usual methods for the determination of $\mathrm{T}_{4}$ were

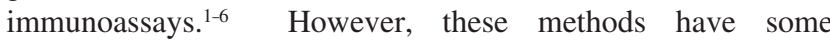
disadvantages, such as expensive instrumentation and complicated operations. The detection of $\mathrm{T}_{4}$ has also been achieved by electrochemical techniques. $\mathrm{T}_{4}$ was determined by differential pulse polarography at a hanging mercury drop electrode (HMDE). ${ }^{7}$ The cathodic reduction of $\mathrm{T}_{4}$ on silver electrode was studied by Iwamoto and co-workers. ${ }^{8}$ In comparison with its multi-step reduction at $\mathrm{HMDE}, \mathrm{T}_{4}$ underwent a one-step reduction on silver; eight electrons were involved in this reduction. $\mathrm{T}_{4}$ in urine has been determined by cathodic stripping square-wave voltammetry at HMDE; a low detection limit of $2.71 \mathrm{ng} / \mathrm{ml}$ was achieved. ${ }^{9}$ However, the employment of a mercury electrode is unsuitable in the interests of environment protection. The successful use of noble metals as electrode materials to catalyze the reduction of $\mathrm{T}_{4}$ may arise from the special interactions of halogen with these metals. No works on the determination of $\mathrm{T}_{4}$ at solid electrodes have been reported, except for silver electrodes. ${ }^{8}$ This may be attributed to poor electrochemical responses of $\mathrm{T}_{4}$ at these kinds of electrodes.

Surfactants are a kind of amphiphilic molecules with a polar head on the one side and a long hydrophobic tail on the other. The applications of surfactants in electrochemistry and electroanalytical chemistry have been widely reported. ${ }^{10} \mathrm{Hu}$ 's group $^{11-14}$ has used surfactants in electroanalytical chemistry to improve the detection limits of some biomolecules. They

$\doteqdot$ To whom correspondence should be addressed.

E-mail: sshu@whu.edu.cn proposed a "synergistic adsorption" mechanism to interpret the enhancement effect of surfactants. Digua et al. ${ }^{15-17}$ mixed the amphiphile hexadecyl sulfonic acid into carbon paste to produce a surfactant-modified carbon paste electrode. This electrode exhibited strong cation exchange property and an improved electron transfer rate between the substrates and the electrode. Falaras et al. ${ }^{18-20}$ prepared an organoclay-modified glassy carbon electrode coated by a cationic surfactant bilayer. They found that this electrode possessed anion-exchange ability and could accumulate both negatively charged metal complexes and neutral redox active reagents. $\mathrm{We}^{21}$ have developed a cetyltrimethylammonium bromide (CTAB)-modified carbon paste electrode based on the surface modification methods. The electrochemical response of $\mathrm{K}_{4} \mathrm{Fe}(\mathrm{CN})_{6}$ at this electrode revealed that CTAB formed a stable monolayer on the electrode surface based on the hydrophobic interaction between the hydrophobic long chain of CTAB and the paraffin oil in carbon paste.

In this paper, a simple and sensitive voltammetric method is presented for the detection of $\mathrm{T}_{4}$ based on the enhanced reduction of $\mathrm{T}_{4}$ at CPE in the presence of CTAB. Similar to the formation of a special ion complex of halogen, $\mathrm{I}_{2} \mathrm{Cl}^{-}, \mathrm{Br}^{-}$in $\mathrm{CTAB}$ may form an ion complex with iodine atoms on $\mathrm{T}_{4}$ and thus facilitate its reduction. This assumption was confirmed by the various electrochemical responses of $T_{4}$ at $C P E$ in the presence of surfactants. As a method for the detection of $\mathrm{T}_{4}$, the reduction process was more suitable than the oxidation process because the selectivity of the reduction was much higher.

\section{Experimental}

\section{Apparatus}

Electrochemical measurements were carried out with a $\mathrm{CHI}$ 


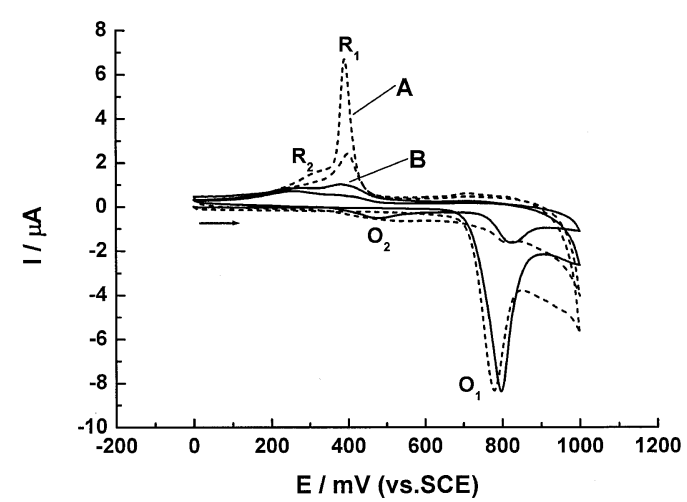

Fig. 1 Electrochemical responses of $5 \times 10^{-6} \mathrm{M}$ thyroxine at $\mathrm{CPE}$ in $0.1 \mathrm{M} \mathrm{HCl}: \mathrm{A}$, in the presence of $6 \times 10^{-5} \mathrm{M} \mathrm{CTAB}$; $\mathrm{B}$, in the absence of $6 \times 10^{-5} \mathrm{M}$ CTAB. Potential scan direction: from 0.0 to $1.0 \mathrm{~V}$; scan rate, $100 \mathrm{mV} / \mathrm{s}$; accumulation, $5 \mathrm{~min}$ at an open circuit.<smiles>NC(Cc1cc(I)c(Oc2cc(I)c(O)c(I)c2)c(I)c1)C(=O)O</smiles>

Fig. 2 Schematic representation of $\mathrm{T}_{4}$ structure.

830 electrochemical analyzer (Shanghai Chenhua Co., China) in a conventional three-electrode system. The working electrode was a carbon paste electrode. A Pt wire and a saturated calomel electrode (SCE) were used as the counter and the reference electrode, respectively.

\section{Reagents}

$\mathrm{T}_{4}$ stock solutions $\left(5 \times 10^{-4} \mathrm{M}\right)$ were prepared by adding $\mathrm{T}_{4}$ (obtained from Sigma, USA) to $0.1 \mathrm{M} \mathrm{NaOH}$ ethanol solution; they were kept in darkness at $4^{\circ} \mathrm{C}$. Surfactants (purchased from Shanghai Reagent Co., China) were dissolved in water to form 1 $\times 10^{-2} \mathrm{M}$ solutions. Other chemicals used were of analytical grade, except for the spectroscopically pure graphite powder. All solutions were prepared with doubly distilled water and all chemicals were used without further purification. Thyroid gland tablets were the gift of Ji'nan Biochemical Pharmaceutical Co., China.

\section{Preparation of carbon paste electrode}

A $25-\mu 1$ volume of paraffin oil was added to $100 \mathrm{mg}$ of spectroscopically pure graphite powder to prepare a homogeneous carbon paste. This carbon paste was then packed into a piston Teflon-tube electrode ( $4.5 \mathrm{~mm}$ in diameter). Prior to measurement, the modified electrode was smoothed on a piece of transparent paper to get a fresh surface.

\section{Procedure}

Measured volumes of $0.1 \mathrm{M} \mathrm{HCl}$ and $60 \mu \mathrm{L}$ CTAB solution were pipetted into an electrochemical cell. Then the standard solution of $\mathrm{T}_{4}$ was added to the cell to form a $10 \mathrm{ml}$ mixture solution. An accumulation potential of $0.9 \mathrm{~V}$ was applied to the working electrode for $5 \mathrm{~min}$ while the solution was stirred. The voltammograms of $\mathrm{T}_{4}$ in the potential range of $0.0-1.0 \mathrm{~V}$ were recorded. Four apparent peaks appeared, of which the sensitive reduction peak at about $0.40 \mathrm{~V}$ was used for the determination

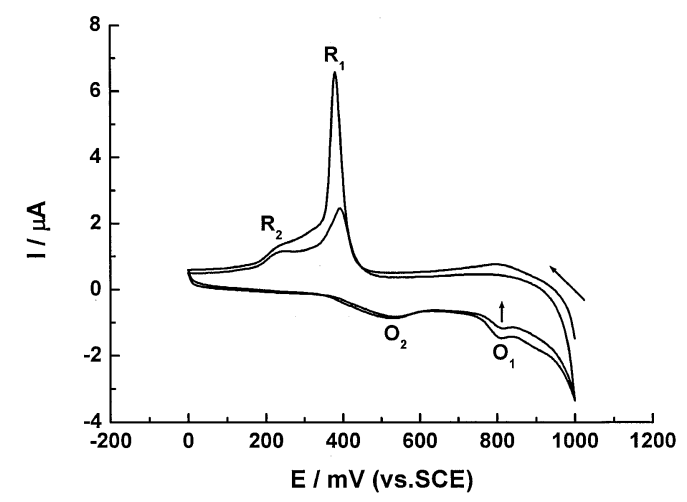

Fig. 3 Multicyclic voltammograms of $5 \times 10^{-6} \mathrm{M} \mathrm{T}_{4}$ in $0.1 \mathrm{M} \mathrm{HCl}$ at $\mathrm{CPE}$ in the presence of $6 \times 10^{-5} \mathrm{M} \mathrm{CTAB}$. Potential scan direction: from 1.0 to $0.0 \mathrm{~V}$; scan rate, $100 \mathrm{mV} / \mathrm{s}$; accumulation, 5 min at an open circuit.

of $\mathrm{T}_{4}$. The cell was kept under darkness during all measurements to avoid the decomposition of $\mathrm{T}_{4}{ }^{8}$

\section{Results and Discussion}

Cyclic voltammograms of $T_{4}$ in acidic media at $C P E$ in the presence of $C T A B$

Figure 1A shows the cyclic voltammograms of $\mathrm{T}_{4}$ at $\mathrm{CPE}$, which were investigated in $0.1 \mathrm{M} \mathrm{HCl}$ containing $6 \times 10^{-5} \mathrm{M}$ $\mathrm{CTAB}$. When the potential initially sweeps from 0 to $1.0 \mathrm{~V}$, a well-defined oxidation peak at $0.80 \mathrm{~V}\left(\mathrm{O}_{1}\right)$ in the positive scan and two reduction peaks at $0.40 \mathrm{~V}\left(\mathrm{R}_{1}\right)$ and $0.27 \mathrm{~V}\left(\mathrm{R}_{2}\right)$ on the scan reversal are observed in the first cycle. In the following cycles, the peak currents of $\mathrm{O}_{1}$ and $\mathrm{R}_{1}$ decrease greatly and a new oxidation peak appears at about $0.48 \mathrm{~V}\left(\mathrm{O}_{2}\right)$. The peak currents of $\mathrm{O}_{1}$ and $\mathrm{R}_{1}$ decrease with the increasing of scan number while those of $\mathrm{O}_{2}$ and $\mathrm{R}_{2}$ remain stable. These results indicate that the electrochemical behaviors of $\mathrm{T}_{4}$ at $\mathrm{CPE}$ are totally irreversible and that the products are strongly adsorbed on the electrode surface, blocking the mass transfer of $\mathrm{T}_{4}$ from the solution to the electrode surface. According to Murphy, ${ }^{22}$ the appearance of $\mathrm{O}_{1}$ is due to the oxidation of $\mathrm{OH}$ on the phenol moiety of $\mathrm{T}_{4}$. From the structure of $\mathrm{T}_{4}$ (Fig. 2), it is clear that $R_{1}$ may be the reduction peak of iodine atoms on $T_{4}$, since only iodine atoms could be electrochemically reduced in this potential window. As for $\mathrm{O}_{2}$ and $\mathrm{R}_{2}$, they are ascribed to the electrochemical responses of the product of $\mathrm{T}_{4}$, i.e., the hydroquinone-benzoquinone redox system produced from the oxidation of $\mathrm{OH}$ on $\mathrm{T}_{4}{ }^{22}$ In the absence of CTAB, the signal of $\mathrm{T}_{4}$ at bare CPE hardly changes except for the greatly depressed $\mathrm{R}_{1}$ and the slight shift of oxidation potential of $\mathrm{O}_{1}$ to the positive direction (Fig. 1B). These results indicate that CTAB can greatly enhance the reduction current of $\mathrm{T}_{4}$ and produces negligible effect on the oxidation reaction.

Mechanism for the reduction/oxidation of $T_{4}$ at $C P E$ in the presence of CTAB

Although the proper electrochemical reactions involved in the reduction/oxidation of $\mathrm{T}_{4}$ have been proposed, the hidden relationships between these responses were still unknown. Figure 3 shows the cyclic voltammograms of $\mathrm{T}_{4}$ at $\mathrm{CPE}$ in the presence of $6 \times 10^{-5} \mathrm{M} \mathrm{CTAB}$ when the potential initially sweeps from 1.0 to $0.0 \mathrm{~V}$. The peak current and the peak 


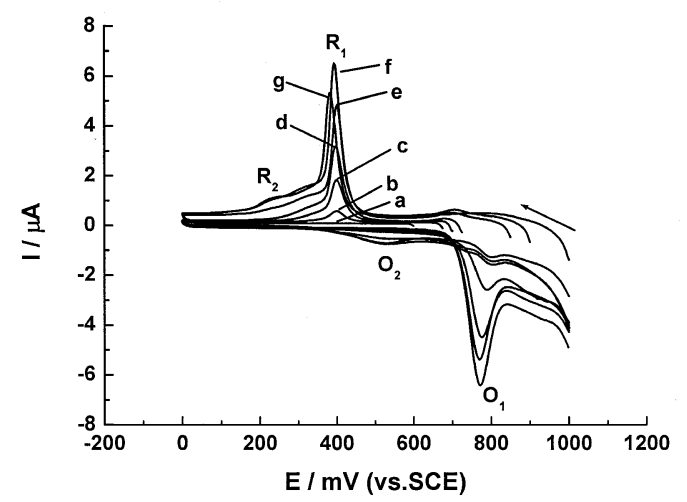

Fig. 4 Effect of initial potential (IP) on the voltammograms of $\mathrm{T}_{4}$ : a, $600 \mathrm{mV}$; b, $680 \mathrm{mV}$; c, $700 \mathrm{mV}$; d, $730 \mathrm{mV}$; e, $850 \mathrm{mV}$; f, 900 $\mathrm{mV} ; \mathrm{g}, 1000 \mathrm{mV}$. Other conditions are the same as in Fig. 3 .

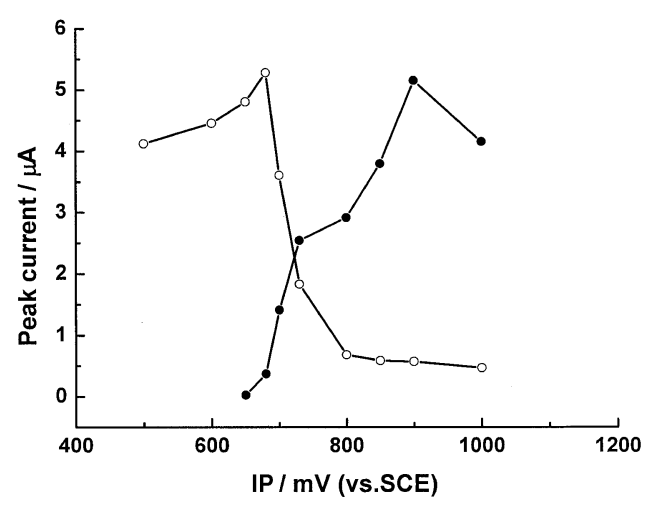

Fig. 5 Variations of peak currents with initial potential (IP) for $\mathrm{O}_{1}$ $(\mathrm{O})$ and $\mathrm{R}_{1}(\bullet)$. Other conditions are the same as in Fig. 3.

potential of $R_{1}$ have almost the same values as those in Fig. 1A. However, in the reverse scan, the peak current of $\mathrm{O}_{1}$ is significantly repressed and tends to remain stable in the following cycles, close to the value of the second cycle in Fig. 1A. These results can be interpreted as the strong adsorption of the reduction product of $\mathrm{T}_{4}$ at the electrode surface. When the electrode potential was scanned over the range of $0.6-1.0 \mathrm{~V}$, the signal of $\mathrm{OH}$ changed little, while no apparent peaks were observed in the range of $0.6-0.0 \mathrm{~V}$ (not shown). Such results suggested an inevitable relationship between the oxidation of $\mathrm{OH}$ and the reduction of the iodine atoms on $\mathrm{T}_{4}$. Figure 4 shows the variations of the voltammetric responses of $\mathrm{T}_{4}$ with the initial potential (IP). It is obvious that the initial potential has remarkable effects on the reduction and the oxidation peak currents of $\mathrm{T}_{4}$, while it shows negligible effects on the peak potentials. The effects of initial potential on reduction/oxidation peak currents are represented in Fig. 5. When the initial potential is more negative than $0.6 \mathrm{~V}, \mathrm{R}_{1}$ is undiscerned and $\mathrm{O}_{1}$ is large. However, when the initial potential arrives at $0.68 \mathrm{~V}$, where the oxidation of $\mathrm{OH}$ begins (see $\mathrm{O}_{1}$ in Fig. 4), the reduction peak of $\mathrm{R}_{1}$ appears. With the further shift of the initial potential to the positive direction, the peak current of $R_{1}$ increases correspondingly except for a small drop of peak current at initial potentials more positive than $0.9 \mathrm{~V}$. The variations in the oxidation of $\mathrm{OH}$ with the positive shift of initial potential are different. The peak current of $\mathrm{O}_{1}$ firstly increases with the positive shift of initial potential up to $0.68 \mathrm{~V}$. When the initial potential approaches $0.68 \mathrm{~V}$, the peak current
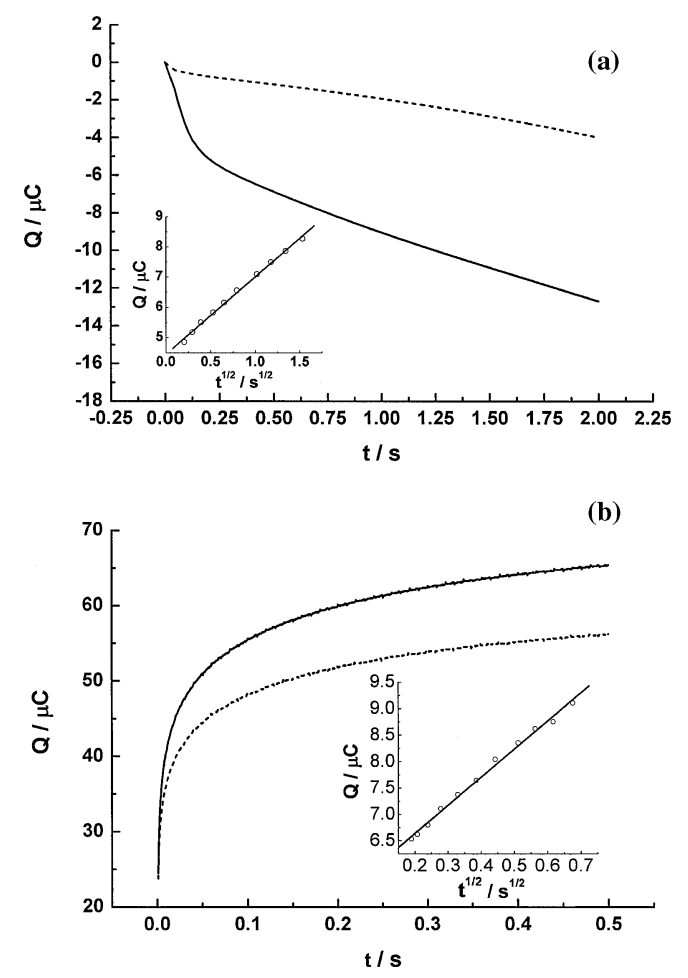

Fig. 6 Chronocoulometry at CPE in the presence $6 \times 10^{-5} \mathrm{M} \mathrm{CTAB}$ for: (a) the oxidation process of $5 \times 10^{-6} \mathrm{M} \mathrm{T}_{4}$, initial potential $0.6 \mathrm{~V}$, final potential $0.9 \mathrm{~V}$, pulse width $4 \mathrm{~s}$; (b) the reduction process of $\mathrm{T}_{4}$, initial potential $0.5 \mathrm{~V}$, final potential $0.35 \mathrm{~V}$, pulse width $0.5 \mathrm{~s}$. The solid line curves stand for the presence of $5 \times 10^{-6} \mathrm{M} \mathrm{T}_{4}$ while those in dot lines are obtained from the blank solutions. Insets show the linear relationships between charges $(Q)$ and the square roots of time $\left(t^{1 / 2}\right)$ (background subtracted).

of $\mathrm{O}_{1}$ arrives at a maximum value. The further increase of initial potential leads to a decrease of the peak current. It is obvious that the oxidation of $\mathrm{OH}$ is apparently restrained when the reduction of $\mathrm{T}_{4}$ begins. These results prove that the reduction of the iodine atoms on $\mathrm{T}_{4}$ is achieved only after the oxidation of $\mathrm{OH}$ on $\mathrm{T}_{4}$. The above conclusion is authentic, because the iodine atoms on the phenol group of $\mathrm{T}_{4}$ are activated after the stable benzene ring is destroyed during the oxidation process and are reduced through the inducement effect of $\mathrm{Br}^{-}$in $\mathrm{CTAB}$.

Chronocoulometry was also employed to characterize the electrochemical responses of $\mathrm{T}_{4}$ at $\mathrm{CPE}$ in the presence of CTAB. Figure 6 shows the chronocoulometry of the oxidation of $\mathrm{OH}$ (Fig. 6a) and the reduction of iodine atoms (Fig. 6b) on $\mathrm{T}_{4}$. It is clear that the charges $(Q)$ have linear relationships with the square roots of time $\left(t^{1 / 2}\right)$ for both the oxidation and the reduction reactions (background subtracted; insets in Figs. 6a and $6 \mathrm{~b})$. According to the integrated Cottrell equation:

$$
Q=\frac{2 n F A C^{\mathrm{b}} D^{1 / 2} t^{1 / 2}}{\pi^{1 / 2}}
$$

where $n$ is the number of the electrons transferred in the studied electrochemical reaction, $A$ is the working electrode area, $C^{\mathrm{b}}$ is the bulk solution of the substrate, $D$ is the diffusion coefficient of the substrate, and the other symbols have their usual significance. The value of $n$ can be obtained when the other parameters in Eq. (1) are known. Because the reduction and the oxidation of $\mathrm{T}_{4}$ show negligible effects on the dimension of $\mathrm{T}_{4}$, 


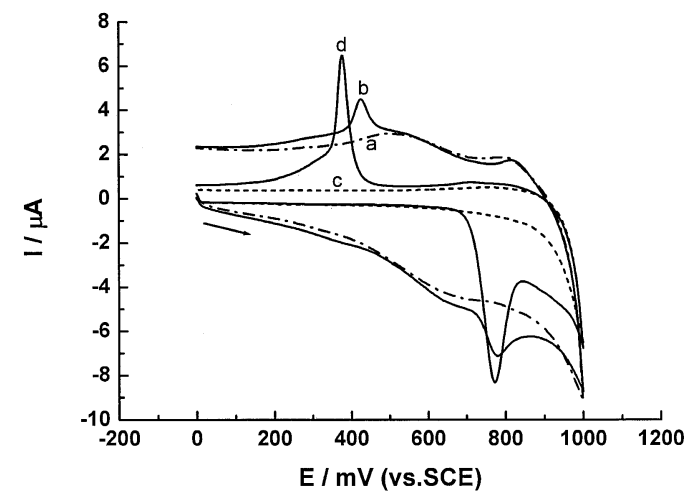

Fig. 7 Voltammograms obtained at glassy carbon electrode (a, b) and at carbon paste electrode $(\mathrm{c}, \mathrm{d})$ in $0.1 \mathrm{M} \mathrm{HCl}$ in the presence of 6 $\times 10^{-5} \mathrm{M} \mathrm{CTAB}$ for blank solutions $(\mathrm{a}, \mathrm{c})$ and for $5 \times 10^{-6} \mathrm{M} \mathrm{T}_{4}$ solutions (b, d). Other conditions are the same as in Fig. 1.

the diffusion coefficients in the oxidation and the reduction processes of $\mathrm{T}_{4}$ can be assumed to possess the same value. Then, under the same experimental conditions, the number of electron transfers for the reduction of $\mathrm{T}_{4}$ can be deduced if $n$ of $\mathrm{OH}$ oxidation can be obtained. Under this condition, the ratio of electron transfer between the reduction and the oxidation of $\mathrm{T}_{4}$ deduced from Fig. 5 and Eq. (1) is 2.078. On the assumption that two electrons were transferred in the oxidation of $\mathrm{OH}$ on phenol,,$^{22}$ the electron transfer in the reduction of $\mathrm{T}_{4}$ was four. Because the effect of the $\mathrm{OH}$ oxidation of $\mathrm{T}_{4}$ on the phenyl ring in the middle position can be neglected, it is rational to consider that the reduction only occurs on the phenol ring, i.e., two iodine atoms are involved in the reduction of $\mathrm{T}_{4}$ and reduced to iodide ions.

\section{Effects of CTAB on the reduction of $T_{4}$}

Compared with the low reduction current in the absence of $C T A B$, the reduction current of $R_{1}$ at CPE in the presence of CTAB was greatly enlarged. However, this enhancement effect of $\mathrm{T}_{4}$ reduction was not applicable to glassy carbon electrode (GCE). Figure 7 shows the cyclic voltammograms of $\mathrm{T}_{4}$ at different electrodes. $\mathrm{T}_{4}$ exhibits a poor electrochemical response at GCE in the presence of CTAB. Although the reduction and the oxidation of $\mathrm{T}_{4}$ are observed, the peak currents are low and the background is large and anomalous. On the contrary, the current response of $\mathrm{T}_{4}$ at $\mathrm{CPE}$ in the presence of CTAB is well-defined and the background is greatly restrained. From the above discussions, one can conclude that the enhanced reduction of $\mathrm{T}_{4}$ is accomplished through the interactions between $\mathrm{T}_{4}, \mathrm{CTAB}$ and the hydrophobic surface of CPE. Figure 8 shows the cyclic voltammograms of $\mathrm{T}_{4}$ reduction at $\mathrm{CPE}$ in the presence of $5 \times 10^{-6} \mathrm{M}$ different surfactants. In the presence of $\mathrm{CTAB}$, the reduction current is the highest and STAB takes the second place, followed by CPB. The presence of other cationic surfactants with shorter hydrophobic tails and the neutral surfactant, Triton $\mathrm{X}-100$, produced neglectable effects on the reduction of $\mathrm{T}_{4}$. When an anionic surfactant, sodium dodecyl sulfonate (SDS), was added to the working solution, the reduction current was completely depressed. These results suggest that only the cationic surfactants with long hydrophobic tails can effectively improve the reduction of $\mathrm{T}_{4}$. Considering the strong interaction between iodine molecules and iodide ions, we suggest that bromide ions in cationic surfactants may form special ion complexes with $\mathrm{T}_{4}$ through the interactions with the iodine atoms on $\mathrm{T}_{4}$, which can promote the

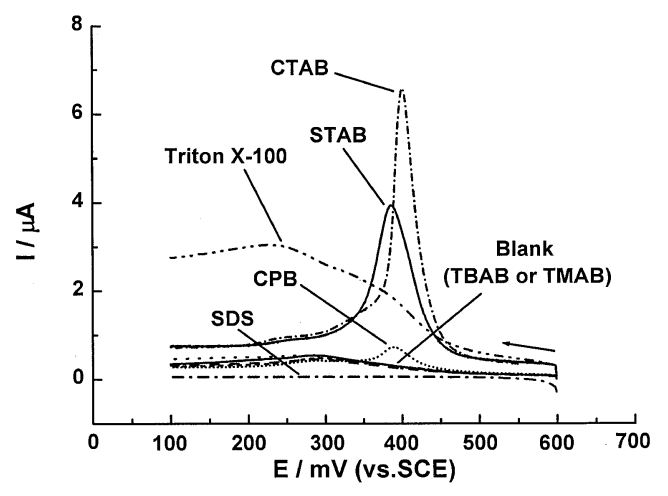

Fig. 8 Electrochemical responses of $5 \times 10^{-6} \mathrm{M} \mathrm{T}_{4}$ at CPE in $0.1 \mathrm{M}$ $\mathrm{HCl}$ containing $6 \times 10^{-5} \mathrm{M}$ of stearyltrimethylammonium bromide (STAB), cetyltrimethylammonium bromide (CTAB), cetylpyridinium bromide (CPB), lauryltrimethylammonium bromide (LTAB), tetrabutylammonium bromide (TBAB), tetramethylammonium bromide (TMAB), Triton X-100, sodium dodecyl sulfonate (SDS) and no surfactant. Accumulation time, $5 \mathrm{~min}$; accumulation potential, $0.9 \mathrm{~V}$; scan rate, $100 \mathrm{mV} / \mathrm{s}$.

reduction of $\mathrm{T}_{4}$. This explanation is consistent with the increasingly enhanced reduction of $\mathrm{T}_{4}$ with the increase of the surfactant activity. The above assumption about the role of CTAB was also supported by the neglectable change of the electrochemical signals of $\mathrm{T}_{4}$ at $\mathrm{CPE}$ with the addition of potassium bromide (KBr) (not shown). The effect of CTAB concentration on the peak current of $R_{1}$ was examined. The peak current increased with the increase of CTAB concentration when $\mathrm{CTAB}$ concentration was lower than $6 \times 10^{-5} \mathrm{M}$, due to the adsorption of more CTAB molecules on the electrode surface. At the CTAB concentration of $6 \times 10^{-5} \mathrm{M}$, the peak current of $R_{1}$ was the highest. With the continuous increase of CTAB concentration, the peak current dropped; this drop was attributed to the block of mass transfer of $T_{4}$ by the compact film of CTAB on the electrode surface. On the basis of the above discussions, it is reasonable to assume that the adsorption of CTAB on the hydrophobic surface of CPE may not only enhance the adsorption of $\mathrm{T}_{4}$ at this surface by hydrophobic interaction but also may concentrate sufficient $\mathrm{Br}^{-}$ions at the electrode surface for the inducement of $\mathrm{T}_{4}$ reduction, which would account for the enhanced reduction of $\mathrm{T}_{4}$ at $\mathrm{CPE}$ in the presence of trace CTAB.

\section{Optimizing of some experimental conditions}

Although the oxidation of $\mathrm{OH}$ on $\mathrm{T}_{4}$ is sensitive for the detection, the interferences of this peak were serious because many compounds containing a phenol hydroxyl group may interfere with the electrochemical response. Thus, the enhancement effect for $\mathrm{CTAB}$ on $\mathrm{T}_{4}$ reduction provides a potential and selective method for the detection of $\mathrm{T}_{4}$. To gain the best results, some experimental conditions for the reduction of $\mathrm{T}_{4}$ were optimized.

The electrochemical responses of $\mathrm{T}_{4}$ in $\mathrm{HCl}, \mathrm{HNO}_{3}$ and $\mathrm{H}_{2} \mathrm{SO}_{4}$ media were tested. It was found that $0.1 \mathrm{M} \mathrm{HCl}$ is a suitable electrolyte for the determination of $\mathrm{T}_{4}$. The effect of $\mathrm{pH}$ on the reduction of $\mathrm{T}_{4}$ was estimated in the range of $\mathrm{pH} 1-6$, and the reduction current decreased with the increasing of $\mathrm{pH}$. The relationship between the peak potential and $\mathrm{pH}$ is complicated. With the increasing of $\mathrm{pH}$, the peak potential positively shifted and reached a maximum at $\mathrm{pH}$. Then it negatively shifted with the further increasing of $\mathrm{pH}$. In the range of $\mathrm{pH} 1-3$, the 
peak potential $\left(E_{\mathrm{p}}\right)$ is linear with $\mathrm{pH}$ :

$$
E_{\mathrm{p}}=0.029+0.3716 \mathrm{pH} \quad(R=0.9933)
$$

One can see from the above equation that the number of the electrons transferred in the reduction of $\mathrm{T}_{4}$ is twice the number of protons, which is consistent with the proposed mechanism for the reduction of $\mathrm{T}_{4}$. The effect of scan rate $(v)$ on the peak current was also investigated. The peak current linearly increased with the increase of scan rate in the range of $10-50$ $\mathrm{mV} / \mathrm{s}$. It seems that the electrode process is controlled by adsorption, which is in accordance with the decreasing of the peak current of $\mathrm{O}_{1}$ in Fig. 1 with the increasing of scan number. The relationship between the peak potential and scan rate can be described by the following equation:

$$
E_{\mathrm{p}}=-0.0211 n v+0.532
$$

The reduction of $T_{4}$ is a totally irreversible process; thus the value calculated for $\alpha \mathrm{n}_{\alpha}$ from Eq. (3) is 0.84 , where $\alpha$ is the transfer coefficient and $n_{\alpha}$ is the number of electrons transferred in the rate-determining step.

The accumulation potential is a major factor that affects the response sensitivity, since the reduction of $\mathrm{T}_{4}$ is adsorptioncontrolled. In the potential range of $0.8-1.2 \mathrm{~V}$, the peak current firstly increased with the increasing of the accumulation potential for an accumulation time of $5 \mathrm{~min}$. Then the peak current reached a maximum value at about $0.9 \mathrm{~V}$ and fell down with the continuous increasing of the accumulation potential. Thus, an optimal accumulation potential of $0.9 \mathrm{~V}$ was selected in the sequential investigations.

\section{Interferences}

Trace substances commonly present in drugs were tested in order to check for interferences with respect to the responses. Interferent-to-analyst ratios in the range of 1:1 to 100:1 were examined for a $\mathrm{T}_{4}$ concentration of $2.5 \times 10^{-6} \mathrm{M}$. The interferences from two fold of estradiol, cholesterol, dopamine and uric acid, 100-fold of ascorbic acid, 40-fold of barbitone, are apparent, while the interference by two fold of estriol is serious. As for tyrosine, the interference is negligible. Comparing the structure of $\mathrm{T}_{4}$ with these interferents, we conclude that the interferences caused by these interferents are due to their competitive combination with $\mathrm{CTAB}$ or their competitive occupation of active points on the electrode surface with $\mathrm{T}_{4}$. The high selectivity of the determination of $\mathrm{T}_{4}$ arises from the specific reduction of iodine atoms on $T_{4}$ instead of from the oxidation of the $\mathrm{OH}$ group.

\section{Calibration and application}

The calibration curve has been established in the concentration range of $2 \times 10^{-7}-9 \times 10^{-6} \mathrm{M}$, and the relationship between the concentration of $\mathrm{T}_{4}$ and the peak current can be described with the following linear regression equations:

$$
I_{\mathrm{p}}=0.286 c+0.316 \quad(R=0.9968)
$$

(in the concentration range of $4 \times 10^{-8}-1 \times 10^{-7} \mathrm{M}$ );

$$
I_{\mathrm{p}}=0.860 c+3.113 \quad(R=0.9959)
$$

(in the concentration range of $1 \times 10^{-7}-1 \times 10^{-6} \mathrm{M}$ );

$$
I_{\mathrm{p}}=5.736 c+7.696 \quad(R=0.9877)
$$

(in the concentration range of $1 \times 10^{-6}-1 \times 10^{-5} \mathrm{M}$ ).
Table 1 Data obtained from the determination of $\mathrm{T}_{4}$ in a drug at $\mathrm{CPE}$ in $0.1 \mathrm{M} \mathrm{HCl}$ in the presence of $6 \times 10^{-5} \mathrm{M} \mathrm{CTAB}$ by linear sweep voltammetry (LSV)

\begin{tabular}{ccccc}
\hline $\begin{array}{c}\text { Drug } \\
\text { sample }\end{array}$ & $\begin{array}{c}\mathrm{T}_{4} \text { labeled } \\
(\mu \mathrm{g} / \text { tablet })\end{array}$ & $\begin{array}{c}\mathrm{T}_{4} \text { found } \\
(\mu \mathrm{g} / \text { tablet })\end{array}$ & $\begin{array}{c}\mathrm{T}_{4} \text { average } \\
(\mu \mathrm{g} / \text { tablet })\end{array}$ & $\begin{array}{c}\mathrm{RSD}, \\
\%\end{array}$ \\
\hline 1 & 40 & 42.1 & & \\
2 & 40 & 39.1 & & \\
3 & 40 & 38.5 & 40.7 & 4.9 \\
4 & 40 & 41.5 & & \\
5 & 40 & 42.3 & & \\
\hline
\end{tabular}

Concentration of thyroxine, $2.5 \times 10^{-6} \mathrm{M}$; accumulation time, $5 \mathrm{~min}$; accumulation potential, $0.9 \mathrm{~V}$; potential scan range, $0.6-0.1 \mathrm{~V}$; scan rate, $100 \mathrm{mV} / \mathrm{s}$.

For an accumulation time of $5 \mathrm{~min}$ at $0.9 \mathrm{~V}$, a detection limit of $6.5 \times 10^{-9} \mathrm{M}$ was obtained $(\sigma=3)$. The relative standard deviation was $4.1 \%$ for six parallel detections of $2.5 \times 10^{-6} \mathrm{M} \mathrm{T}_{4}$ at the same electrode, refreshed.

The method developed was employed for the determination of $\mathrm{T}_{4}$ in drugs. The drugs were pretreated according to a previous report. ${ }^{7}$ Table 1 gives the results of $\mathrm{T}_{4}$ detection in a kind of drug that was used for the treatment of hypothyroidism. This drug contains tissues of thyroid glands instead of thyroxine itself. In body liquid, thyroxine is released from this drug and exhibits its biological function. As can be seen from Table 1, good recoveries and the low relative standard deviation (RSD) are obtained. Thus, this method is sensitive and authentic for the detection of $\mathrm{T}_{4}$ in drugs.

\section{Conclusions}

The electrochemical reduction of thyroxine $\left(\mathrm{T}_{4}\right)$ at carbon paste electrode (CPE) was investigated. The results showed that the reduction of $\mathrm{T}_{4}$ was significantly improved in the presence of cetyltrimethylammonium bromide (CTAB). This was achieved through two important roles of CTAB: (i) the enhanced adsorption of $\mathrm{T}_{4}$ by the hydrophobic interaction between $\mathrm{T}_{4}$ and the adsorbed CTAB on the hydrophobic surface of CPE; (ii) the activation of iodine atoms on $\mathrm{T}_{4}$ by the complexing interactions with bromide ions $\left(\mathrm{Br}^{-}\right)$in $\mathrm{CTAB}$ that are accumulated near the electrode surface beforehand by the positively charged CTAB film on the electrode surface. The chronocoulometry studies showed that the reduction reaction occurred at the two iodine atoms on the phenol group of $\mathrm{T}_{4}$, producing two iodide ions. Compared with the oxidation reaction of $\mathrm{T}_{4}$, the reduction peak was more selective for the determination of $\mathrm{T}_{4}$ while showing almost the same sensitivity. The interference and the calibration experiments showed that the media system developed in this work may be put into practice for the detection of $\mathrm{T}_{4}$.

\section{Acknowledgements}

(4) This research was supported by the National Natural Science Foundation of China (Nos. 60171023 and 30370397) and the Science Foundation of Qujing Normal College (No. 0313901).

\section{References}

1. D. Schmalzing, L. B. Koutny, T. A. Taylor, W. Nashabeh, 
and M. Fuchs, J. Chromatogr. B: Biomed. Appl., 1997, 697(1-2), 175.

2. S. Georgous and I. Christofidis, Clin. Chim. Acta, 1996, 244(2), 209.

3. A. Zimlich II and D. S. Hage, Anal. Chim. Acta, 2002, 470, 37.

4. H. Silvaieh, R. Wintersteiger, M. G. Schmid, O. Hofstetter, V. Schurig, and G. Gubitz, Anal. Chim. Acta, 2002, 463, 5.

5. M. I. Becker, J. E. Aguayo, A. Jamett, F. Juica, A. Yudelevich, A. Foradori, and A. E. D. Ioannes, J. Immunol. Methods, 1996, 192, 73.

6. C. D. Karapitta, A. Xenakis, A. Papadimitriou, and T. G. Sotiroudis, Clin. Chim. Acta, 2001, 308(1 - 2), 99.

7. E. Jacobsen and W. F. Fonahn, Anal. Chim. Acta, 1980, 119,33

8. M. Iwamoto, A. Webber, and R. A. Osteryoung, Anal. Chem., 1984, 56, 1202.

9. L. Hernandez, P. Hernandez, and O. Nieto, Analyst, 1994, $119,1579$.

10. J. F. Rusling, Acc. Chem. Res., 1991, 24, 75.

11. S. S. Hu, Y. Q. Yan, and Z. F. Zhao, Anal. Chim. Acta,
1991, 248, 103.

12. H. Yi, K. Wu, and S. Hu, Talanta, 2001, 55(6), 1205.

13. S. Zhang, K. Wu, and S. Hu, Talanta, 2002, 58(4), 747.

14. S. Hu, K. Wu, H. Yi, and D. Cui, Anal. Chim. Acta, 2002, 464(2), 209.

15. K. Digua, J. M. Kauffmann, and J. L. Delplancke, Electroanalysis, 1994, 6, 451.

16. K. Digua, J. M. Kauffmann, and J. L. Delplancke, Electroanalysis, 1994, 6, 459.

17. J. R. Posac, M. D. Vazquez, M. L. Tascon, J. A. Acuna, C. D. Fuente, E. Velasco, and P. S. Batanero, Talanta, 1995, 42(2), 293.

18. P. Falaras and D. Petridis, J. Electroanal. Chem., 1992, 337, 229.

19. A. F. Nassar, J. F. Rusling, and T. F. Kumosinski, Biophys. Chem., 1997, 67, 107.

20. H. Carrero and L. E. León, Electrochem. Commun., 2001, $3,417$.

21. C. Hu and S. Hu, Electrochim. Acta, 2004, 49(3), 405.

22. M. A. Murphy, G. D. Wilcox, R. H. Dahm, and F. Marken, Electrochem. Commun., 2003, 5, 51. 